Arq. Bras. Med. Vet. Zootec., v.58, n.6, p.1092-1098, 2006

\title{
Dermatite micobacteriana atípica em gato: relato de caso
}

\author{
[Atypical mycobacterial dermatitis in cat: a case report]
}

\author{
C.E. Larsson ${ }^{1}$, E.H. Delayte ${ }^{1 *}$, A.C. Balda ${ }^{1}$, N.S. Michalany ${ }^{2}$, S.R. Pinheiro ${ }^{1}$, \\ M. Otsuka ${ }^{1}$, E. Roxo ${ }^{3}$ \\ ${ }^{1}$ Faculdade de Medicina Veterinária e Zootecnia -USP \\ Av. Dr. Orlando Marques de Paiva, 87 \\ 05509-000 - São Paulo, SP \\ ${ }^{2}$ Escola Paulista de Medicina - UNIFESP \\ ${ }^{3}$ Instituto Biológico - São Paulo, SP
}

\begin{abstract}
RESUMO
Relata-se, pela primeira vez no Brasil, um caso de dermatite decorrente de infecção por micobactéria atípica do complexo Mycobacterium fortuitum-peregrinum, em espécie felina, sem raça definida, fêmea, com cinco anos de idade. Há oito meses, evoluía com lesões maculares equimóticas, nodulares, erosadas, ulceradas, acompanhadas de fístulas exsudativas, com intenso prurido e algia. Evidenciou-se a presença de micobactéria do complexo Mycobacterium fortuitum-peregrinum (grupo IV de Runyon ) identificada após evidenciação histopatológica, cultivo bacteriano e por testes bioquímicos. Após dois meses de terapia sistêmica com enrofloxacina $(5 \mathrm{mg} / \mathrm{kg} / \mathrm{Bid} / \mathrm{VO})$ e tópica (triclosan e rifamicina) houve involução das lesões, com efeitos colaterais discretos.
\end{abstract}

Palavras-chave: gato, micobacteriose, complexo Mycobacterium fortuitum-peregrinum, dermatite

\begin{abstract}
A case of dermatitis caused by atypical mycobateria of Mycobacterium fortuitum peregrinum complex was observed for the first time in Brazil. A five-year-old female mixed breed cat had a dermatitis process which had started eight months before. Lesions were characterized by macules, nodules, erosions, ulcers and exsudative fistulas, with intensive pruritus and pain. It had failed to respond to clinical treatment and surgical excision. The diagnosis was based on history, physical and dermatologic examination and complementary tests (cytologic, bacterioscopic, bacterial culture, histopathological, hemathological, ultrasonographic, radiographic and electrocardiographic). The presence of mycobacteria of Mycobacterium fortuitum-peregrinum complex (group IV of Runyon) was observed and identified after histopathological evidence, bacterial culture and biochemical tests. After two months of systemic therapy with enrofloxacin $(5 \mathrm{mg} / \mathrm{kg}$, orally/twice a day) and topic treatment with triclosan and rifamicin, rapid improvement of the clinical appearance of the lesions were observed with low incidence of side-effects.
\end{abstract}

Keywords: cat, mycobacteriosis, Mycobacterium fortuitum-peregrinum, dermatitis

\section{INTRODUÇÃO}

Em geral as micobacterioses tegumentares são pouco freqüentes dentre os cães e gatos.
Conhecem-se quatro grupos de dermatopatias relacionadas às enfermidades micobacterianas da pele: micobacteriose cutânea atípica, síndrome

Recebido em 30 de agosto de 2004

Aceito em 3 de março de 2006

*Autor para correspondência (corresponding author)

E-mail: edelayte@yahoo.com.br 
do granuloma lepróide canino, lepra felina e tuberculose cutânea (Lemarie, 1999).

As micobacterioses felinas associadas a infecções por micobacterias atípicas são pouco freqüentes havendo, até o final dos anos 90, apenas 39 relatos dispostos na bibliografia indexada, nos quais não se incluía nenhum caso brasileiro (Scott, 2001).

Nos felinos, as espécies patogênicas comumente evidenciadas são agrupadas no grupo IV da classificação de Runyon, de 1959, e incluem Mycobacterium fortuitum, com três biovariantes (biovar peregrinum, biovar fortuitum e biovar inominata) (Monroe et al.,1988; Lemarie, 1999). Além dessas, as espécies M. phlei, M. smegmatis e $M$. chelonei têm sido incriminadas. Todas são não-cromógenas, de rápido crescimento, Gram positivas, ácido-álcool resistentes, aeróbicas e não formadoras de esporos. São ubíquas na natureza, sendo evidenciadas em águas e solo encharcado, trato entérico de suínos e de espécimens ruminantes, não sendo dotadas de patogenicidade para os animais em circunstâncias normais.

Os gatos, todavia, são mais suscetíveis às infecções micobacterianas, sendo a porta de entrada as lacerações e soluções de continuidade traumáticas (Wilkinson et al., 1978; Studdert e Hughes, 1992). As lesões dispõem-se na região abdominal ventral (meso e hipogástrica), sendo caracteristicamente de decurso longo e recidivante. Constituem-se em máculas purpúricas, nódulos ou gomas, fístulas drenantes, encimadas por crostas. À palpação, o panículo encontra-se espessado, firme e nodular. Raramente, há disseminação sistêmica, embora haja espraiamento panicular e até por fascias musculares (Scott et al., 2001). Deve-se diferenciá-la de outras enfermidades que acarretam nódulos, gomas ou tratos fistulosos, tais como: paniculite nodular, panesteatite, granulomas por corpos estranhos, nocardiose, prototecose, actinomicose, criptococose e esporotricose, pseudo-micetoma, neoplasias, lepra felina, tuberculose e quadros abscedativos secundários a infecções virais imunossupressoras (FelV e FIV).

O diagnóstico não interpõe maiores dificuldades, estribando-se no exame direto de exsudatos ou de decalques de tecido lesado, corados pela técnica de Ziehl-Neelsen, no cultivo bacteriano (Meios de Löwestein-Jensen, Petragnani e Stonebrink) complementado por estudos bioquímicos das cepas isoladas e pelo histopatológico. A terapia envolve o emprego de antibióticos associado ao debridamento cirúrgico (Wilkinson et al., 1982; Studdert e Hughes, 1992; Lemarie, 1999; Scott et al., 2001).

O objetivo deste trabalho é descrever o quadro clínico evidenciado em gato paulista, pela inexistência de relatos, no Brasil, de casos de micobacteriose tegumentar atípica em felinos e pela sua baixa freqüência de ocorrência.

\section{RELATO DE CASO}

Atendeu-se, no inverno de 2000, no Serviço de Dermatologia do Departamento de Clínica Médica e do Hospital Veterinário (HOVET) da Faculdade de Medicina Veterinária e Zootecnia (FMVZ) da Universidade de São Paulo (USP), uma gata nulípara, sem precisa definição racial, castrada, com cinco anos, de pelagem tigrada, com seis quilogramas de peso, criada pelos donos em apartamento em Rio Claro (SP), sem qualquer contato com outros animais. Quando levada à primeira consulta $(11 / 08 / 2000)$, referiu-se ao surgimento, há oito meses, de "nódulo intramamário" (sic). Em clínica veterinária privada, fora firmado o diagnóstico de "neoplasia mamária" (sic). Havia sido submetida, há oito meses (dezembro de 1999) à cirurgia para remoção da "neoformação", que não foi encaminhada a exame histopatológico. No pós-operatório mediato, ao redor do $15^{\circ}$ dia, surgiu novo nódulo abdominal e área de alopecia. No local da cicatriz cirúrgica, logo a seguir, observou-se abertura de ferida não secretante. Na mesma clínica foi re-operada para remoção do novo nódulo que foi, então, encaminhado para diagnóstico histopatológico, estabelecido como "impetigo bacteriano" (sic). Foi, a seguir, interposta medicação à base de corticosteróide (dexametasona) e antibióticos (gentamicina, penicilina associada à estreptomicina e enrofloxacina), sem qualquer resultado. Em novas tentativas de terapia $(30,120$ e 180 dias), após a segunda intervenção cirúrgica, recorreu-se a distintas pomadas cicatrizantes, antibióticos e aplicações (três ocasiões) de corticosteróide de depósito (acetato de metil prednisona ${ }^{1}$ ) em dosagem desconhecida.

${ }^{1}$ Depo Medrol ${ }^{\circledR}$ - Pharmacia \& Upjohn 
Com o agravamento da lesão foi, então, trazida para atendimento no HOVET/USP. Referia-se a prurido intenso nas áreas de lesões. Negavam-se alterações: do apetite, da sede, dos hábitos intestinais e da micção. Afora uma aparente apatia decorrente, segundo o proprietário, da algia tegumentar, não se referia nenhum outro sintoma. O manejo alimentar e a higienização eram adequados.

Ao exame físico, constataram-se: normotermia, normoesfigmia, taquipnéia, hidratada, com mucosas aparentes normocoradas, sem linfadenomegalia e tampouco alterações na ausculta cardiopulmonar e na palpação abdominal. As lesões cutâneas caracterizavam-se como áreas equimóticas, erosadas ou ulceradas, com trajetos fistulosos exsudativos, mesmo sem serem submetidos à expressão (Fig. 1).

Estabelecido o diagnóstico presuntivo de paniculite, de etiologia fúngica (esporotricose ou criptococose) ou bacteriana (micobacteriose típica ou atípica) ou, ainda, de lesões carcinomatosas metastáticas, colheu-se material para cultivo bacteriológico, para bacterioscopia e citologia e para histopatológico de pele, submetendo-a a exames eletrocardiográfico préanestésico, hematológico e ultrassonográfico de abdômen e radiográfico de tórax.

Pelos exames complementares não foram evidenciadas alterações hemáticas, radiográficas ou ultrassonográficas. O laudo eletrocardiográfico foi de taquicardia sinusal. Ao exame citológico, a partir de material aspirado de uma das formações nodulares, observou-se elevada celularidade, mormente de neutrófilos íntegros, segmentados, com presença de grande número de macrófagos com intensa atividade fagocitária. Não foi possível, contudo, a caracterização morfométrica de agentes bacterianos.

Pelo laudo histopatológico, dos quatro fragmentos da pele biopsiada, utilizando-se das colorações de hematoxilina-eosina, PAS e ZiehlNeelsen, evidenciou-se solução de continuidade da epiderme, coberta por crosta necrótica, com denso infiltrado inflamatório, comprometendo toda a derme e parte da hipoderme. Tal infiltrado era constituído por macrófagos, com núcleos arredondados ou ovóides e abundante citoplasma eosinófilo, distribuídos difusamente, formando nódulos de variados tamanhos. Em inúmeros trechos observavam-se aglomerados de neutrófilos, íntegros e degenerados, muitas vezes no centro dos granulomas nodulares. A pesquisa de bacilos ácido-álcool resistentes (BAAR) mostrou-se positiva, pela presença de bacilos longos no citoplasma de macrófagos (Fig. 2).

A pesquisa de estruturas fúngicas, pelo PAS, foi negativa. Estabeleceu-se, então, diagnóstico histopatológico de micobacteriose tegumentar.

Quanto ao exame bacteriológico, à bacterioscopia, o material, corado pelo ZiehlNeelsen, apresentou resultado positivo quanto à presença de micobactérias. Houve, pelas culturas em meio de Petragnani, Löwestein-Jensen e de Stonebrink, crescimento de micobactérias em cinco dias.

As culturas foram encaminhadas ao Laboratório de Tuberculose do Instituto Biológico da Secretaria de Agricultura e Abastecimento de Estado de São Paulo para a identificação, por métodos bioquímicos, da cepa de Mycobacterium sp isolada. Obteve-se, como resultado culturas caracterizadas como acromógenas, de crescimento rápido $\mathrm{e}$ esverdeadas ao envelhecimento. Pelos testes bioquímicos (Tab. 1), constatou-se tratar-se de micobactéria do complexo Mycobacterium fortuitum-peregrinum.

Com o diagnóstico etiológico estabelecido, no primeiro retorno $(23 / 08 / 2000)$, iniciou-se o tratamento com enrofloxacina ${ }^{2}$ (5mg/kg/BID) pela via oral e utilização tópica (BID) de xampu à base de triclosan-DP300 30 e solução de rifamicina ${ }^{4}$ por sobre a área lesada.

Compareceu a dois outros retornos (18/09/2000 e 24/10/2000), referiu-se melhora acentuada das lesões tegumentares, da ordem de $90 \%$, segundo o proprietário e, também, constatada pelo exame físico.

\footnotetext{
${ }^{2}$ Flotril ${ }^{\circledR}$ - Schering Plough

${ }^{3}$ Soapex ${ }^{\circledR}$ - Galderma

${ }^{4}$ Rifocina Spray ${ }^{\circledR}$ - Aventis Pharma
} 


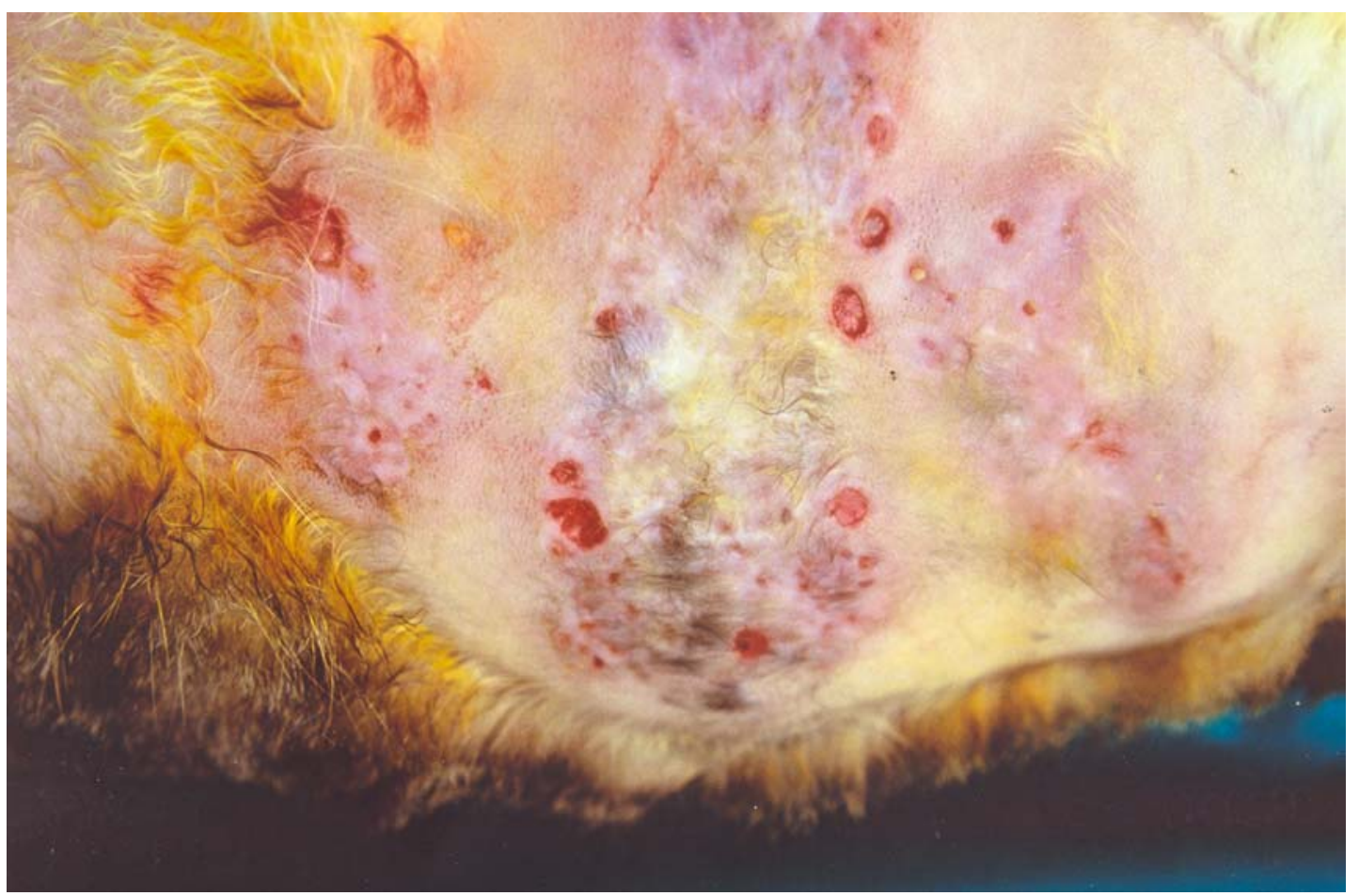

Figura 1. Gata, sem raça definida, cinco anos de idade. Micobacteriose tegumentar - região meso e hipogástrica ventral. Alopecia, fístulas, úlceras, exsudação.

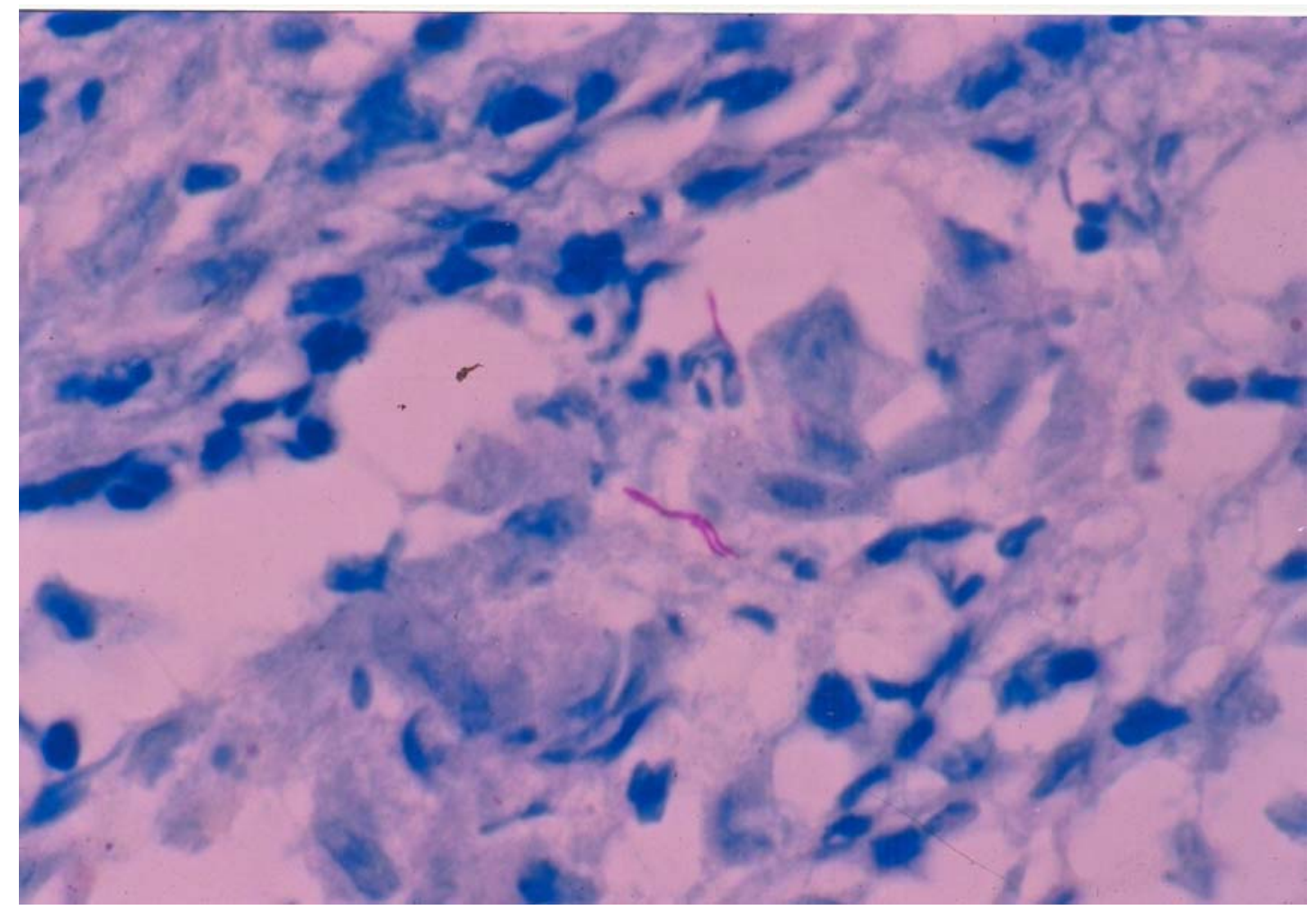

Figura 2. Gata, sem raça definida, cinco anos de idade. Micobacteriose tegumentar -Micobactérias intramacrofágicas (Ziehl-Neelsen 400x). 
Tabela 1. Resultados dos testes bioquímicos em cepa de Mycobacterium fortuitumperegrinum isolada de gata, sem raça definida, cinco anos

\begin{tabular}{lcc} 
Teste & Resultado & Interpretação \\
\hline Captação de ferro & +++ & positivo \\
Catalase à temperatura ambiente & +++ & Positivo \\
Inativação da catalase a $68^{\circ} \mathrm{C}$ & +++ & Positivo \\
Crescimento em ágar nutritivo & +++ & Positivo \\
Crescimento em citrato de sódio & 2 colônias & Inibido \\
Crescimento em frutose & $>100$ & Positivo \\
Crescimento em manitol & 6 colônias & Inibido \\
Crescimento em NaCl & $>100$ & Positivo \\
Hidrólise do "Tween" 80 & 3 dias & Positivo \\
Nitrato & + & Positivo \\
Telurito & 10 dias & Positivo \\
Urease & +++ & Positivo \\
\hline
\end{tabular}

Evidenciou-se cicatrização das lesões anteriormente ulceradas e fistuladas, discreto eritema e áreas de alopecia. Na região inguinal esquerda palpava-se, ainda, formação nodular dermoepidérmica, móvel e macia. Clinicamente, o proprietário referia disorexia progressiva, chegando no último retorno à anorexia, perda de peso (700g), episódios de emese e oligodipsia. Mostrava-se com discreta desidratação, normotérmica, normoesfígmica e normopnéica. Solicitou-se avaliação das funções hepato-renal e realização de ultra-som abdominal. Pelos resultados dos exames complementares, subsidiando o exame físico, concluiu-se que o quadro gastrentérico relacionava-se ao emprego da quinolona. Preconizou-se tratamento de suporte. A partir desta última data $(24 / 10 / 2000)$ não mais o proprietário retornou com o animal.

\section{DISCUSSÃO}

O presente relato justifica-se pela ausência de descrição de micobacteriose tegumentar atípica em felino, no Brasil e a título de alerta por sua possível ocorrência em animais de companhia. Afora as micobacterioses típicas, no Brasil, se tem apenas relato de ocorrência de micobacterioses como a síndrome do granuloma lepróide canino (Larsson et al., 1990; Larsson et al., 1996; Larsson et al., 2000) e de um caso de lepra felina (Larsson, 2002).

O caso apresenta, do ponto de vista clínico, inúmeros pontos em comum com relatos dispostos na bibliografia (Studdert e Hughes, 1992; Lemarie, 1999; Wilkinson et al., 1982; Monroe et al., 1988; Scott et al., 2001; Kipar et al., 2003) relativamente ao local de assestamento, tipo de lesão evidenciada, decurso evolutivo, sintomas manifestados e insucesso à terapia preteritamente empregada, ao menos até o estabelecimento do diagnóstico.

As infecções pelas micobactérias atípicas, também chamadas de oportunistas, parecem ser mais freqüentes em felinos (Scott et al., 2001), em decorrência de traumatismos, inoculação durante brigas, pelo emprego de material cirúrgico ou por agulhas contaminadas.

As lesões localizam-se em qualquer local do tegumento. Em felinos, entretanto, são mais comuns na região abdominal ventro-caudal (inguinal, umbelical) ou lombar. Habitualmente, são indolores e desacompanhadas de linfoadenomegalia, pirexia ou disorexia. Em alguns animais imunossuprimidos pode haver a disseminação da lesão ou evolução com sepsis (Scott et al., 2001).

No caso, a condução inicial não foi a mais adequada, pois o primo diagnóstico foi estabelecido sem os exames complementares necessários (pré e pós-cirúrgico) para confirmar uma suposta neoplasia mamária. Pode-se conjeturar que as lesões iniciais eram decorrentes da micobacteriose ou que esta se instalou durante o procedimento cirúrgico realizado. As infecções micobacterianas nosocomiais iatrogênicas são freqüentes em medicina humana (Monroe et al., 1988) no decorrer de procedimentos invasivos.

As micobacterioses atípicas nos gatos mimetizam outras dermatopatias que cursam com formações sólidas (pápulas ou nódulos) ou 
perdas teciduais (erosões, úlceras e fístulas). Portanto, é necessário, tal como o executado nesse caso, que as diferenciem de paniculites degenerativas (panesteatites), infecciosas (nocardiose, prototecose, esporotricose, dermatofitose, criptococose, actinomicose, tuberculose, lepra) ou por corpos estranhos. Deve-se, também, afastar uma eventual etiologia neoplásica (linforreticular ou mamária) ou abscedativa (abscessos crônicos secundários a infecções virais imunossupressivas).

A despeito de nem sempre ser possível a evidenciação direta do agente, a partir de exsudato ou de fragmento de tecido lesado, corado pelos métodos de Gram ou Ziehl-Neelsen (Monroe et al., 1988), nesse caso, o exame bacterioscópico permitiu a observação de microrganismos álcool-ácido resistentes. O exame histopatológico realizado, tal como o disposto na bibliografia (Scott et al., 2001), propiciou, mesmo antes da identificação microbiológica, elementos para o estabelecimento do diagnóstico. Os achados histológicos de presença de granulomas nodulares, celulite e paniculite tendo de permeio bacilos ácido-álcool resistentes intramacrofágicos são característicos da enfermidade (Lemarie, 1999). As micobactérias são passíveis de visualização em 50\% dos casos, sendo aquelas do grupo das micobactérias de rápido crescimento evidenciadas em número menor relativamente aos agentes do complexo $M$. avium, quais sejam, de crescimento lento (Lemarie, 1999).

Mesmo quando se visualizem BAAR em material corado é imprescindível que se realizem culturas microbianas para que se possa diferenciar as infecções micobacterianas atípicas daquelas originárias dos quadros de lepra felina, nocardiose ou de tuberculose (Lemarie, 1999). Embora a tuberculose, com lesões cutâneas, seja evento raro nos gatos, o aspecto antropozoonótico deve ser levado em conta já que felino infectado por $M$. tuberculosis pode se constituir em indicador da presença da enfermidade nos contactantes humanos.

A caracterização no cultivo, em meios de Lowestein-Jensen e Petragnani, de crescimento aeróbico, rápido, de bacilo não móvel, de forma acromógena, não formador de esporos, ácidoálcool resistente propiciou os elementos necessários para incluí-lo no Grupo IV da classificação, de 1959, de Runyon (Monroe et al., 1988). Mesmo sem recorrer a técnicas de biologia molecular, as provas bioquímicas, realizadas em laboratório referencial, permitiram a inclusão da cepa isolada no complexo Mycobacterium fortuitum-peregrinum.

A caracterização final é de suma importância em termos de escolha do protocolo de tratamento. A resistência a antibióticos por micobactérias do grupo IV tem se tornado problema crescente. Descreveu-se, recentemente, que as três biovariâncias de $M$. fortuitum têm diferentes graus de suscetibilidade ao grupo de antibióticos mais efetivo, que é o das fluorquinolonas (Studdert e Hughes, 1992). Assim, a cepa isolada, no presente relato, $M$. fortuitum peregrinum tem suscetibilidade intermediária às ciprofloxacina e ofloxacina com relação ao $M$. fortuitum fortuitum ou inominata (Lemarie, 1999).

Em termos da conduta medicamentosa eleita, pelo fato das quinolonas sobrepujarem, em eficácia, as tetraciclina, doxiciclina, sulfa potencializada, gentamicina e clofazimina(Studdert e Hughes, 1992), optou-se por tratar a gata com enrofloxacina em dosagem habitual. Droga esta, segura, de baixo custo e de fácil encontro.

O tratamento, de cerca de 60 dias, redundou em flagrante melhora, com involução quase que completa das lesões, embora, ao final do período de tratamento tenha ele gerado indisposição gastroentérica.

A terapia tópica adjuvante, à base de rifamicina, antibiótico bactericida, foi preconizada pela ação micobactericida comprovada, de há muito, pela experiência do Serviço de Dermatologia, no tratamento de casos de micobacteriose atípica (síndrome do granuloma lepróide canino) da pele de cães (Larsson et al., 2000; Malik et al., 2001).

Não se pôde confirmar a plena involução do quadro e propor a alta clínica pelo fato do proprietário não mais comparecer nos retornos aprazados pela alegada longa distância entre o município de residência e o hospital veterinário. 


\section{REFERÊNCIAS BIBLIOGRÁFICAS}

KIPAR, A.; SCHILLER, I.; BAUMGÄRTNER, $\mathrm{W}$. Immunopathological studies on feline cutaneous and (muco) cutaneous mycobacteriosis. Vet. Immunol. Immunopathol., v.91, p.169-182, 2003.

LARSSON, C.E. Abordagem diagnóstica nas dermatoses erodoulcerativas e crostosas. In: DESCOMPLICANDO AS DERMATOSES FELINAS, 2002, São Paulo. Curso...São Paulo: Sociedade Brasileira de Dermatologia Veterinária, 2002. (Notas de aula).

LARSSON, C. E.; MICHALANY, N. S.; PINHEIRO, S. R. et al. Controvérsia en dermatologia - úlceras micobacterianas del perro. In: CONGRESSO PANAMERICANO DE CIÊNCIAS VETERINÁRIAS, 15., 1996, Campo Grande. Anais...Campo Grande, 1996.

LARSSON, C. E.; OTSUKA, M.; MICHALANY, N. S. et al. Canine leproid granuloma syndrome (CLGS) in Brazil (São Paulo) Vet. Dermatol., v.11, suppl.1, p.44, 2000.

LARSSON, C.E.; MICHALANY, N. S.; PINHEIRO, S. R. et al. Micobacterioses atípicas em caninos domésticos - relato de casos em São Paulo, Brasil. In: CONGRESSO BRASILEIRO DE CLÍNICOS VETERINÁRIOS DE PEQUENOS ANIMAIS, 13., 1990, Gramado. Anais... Gramado, 1990.
LEMARIE, S. L. Mycobacterial dermatitis. Vet. Clin. N. Am.: Small Anim. Pract., v.29, p.12911301, 1999.

MALIK, R.; MARTIN, P.; WIGNEY, D. et al . Treatment of canine leproid granuloma syndrome: preliminary findings in seven dogs. Aust. Vet. J., v.79, p.30-35, 2001.

MONROE, W.E.; AUGUST, J. R.; CHICKERING, W. R. et al. Atypical mycobacterial infections in cats. Comp. Cont. Educ., v.10, p.1044-1048, 1988.

SCOTT, D. W.; MILLER Jr., W. H.; GRIFFIN, C. E. Small animal dermatology, 6.ed Philadelphia: W.B. Saunders, 2001 p.312-321.

STUDDERT, V. P.; HUGHES, K. L. Treatment of opportunistic mycobacterial infections with enrofloxacin in cats. J. Am. Vet. Med. Assoc., v.201, p.1388, 1992.

WILKINSON, G. T.; KELLY, W. R.; O'BOYLE, D. Cutaneous granulomas associated with Mycobacterium fortuitum infection in a cat. J. Small Anim. Pract., v.19, p.357-63, 1978.

WILKINSON, G.; KELLY, W.; O'BOYLE, D. Pyogranulomatous panniculitis in cats due to Mycobacterium smegmatis. Aust. Vet. J., v.58, p.77, 1982. 